\title{
BEHAWIORALNA OCENA BÓLU U PACJENTÓW NA ODDZIALE INTENSYWNEJ TERAPII - WYNIKI WSTĘPNE
}

\section{BEHAVIORAL ASSESSMENT OF PAIN IN PATIENTS IN THE INTENSIVE CARE UNIT - PRELIMINARY RESULTS}

\author{
Edyta Katarzyna Cudak¹, Danuta Dyk ${ }^{1}$, Aleksandra Gutysz-Wojnicka², Bożena Nowaczyk ${ }^{1}$, \\ Celina Glaza' ${ }^{1}$, Dorota Kazimierska', Sylwia Miętkiewicz' \\ ${ }^{1}$ Zakład Pielęgniarstwa Anestezjologicznego i Intensywnej Opieki, Wydział Nauk o Zdrowiu \\ Uniwersytet Medyczny im. Karola Marcinkowskiego w Poznaniu \\ ${ }^{2}$ Katedra Pielęgniarstwa, Wydział Nauk Medycznych \\ Uniwersytet Warmińsko-Mazurski w Olsztynie
}

DOI: https://doi.org/10.20883/pielpol.2018.18

\section{STRESZCZENIE}

Wstęp. Zgodnie z definicją ból jest subiektywnym odczuciem, którego intensywność może być opisana przez osobę ten ból odczuwającą. Jest wiele grup pacjentów, którzy z różnych powodów nie są w stanie zwerbalizować odczuwanego bólu. Ocena bólu odczuwanego przez pacjentów oddziałów intensywnej terapii jest związana z sedacją tych pacjentów, zaburzeniami komunikacji werbalnej oraz prowadzeniem sztucznej wentylacji.

Cel. Celem opracowania była dokonana u krytycznie chorych pacjentów ocena bólu z użyciem behawioralnych wskaźników, oparta na polskiej wersji skali Critical Care Pain Observation Tool (CPOT). Materiał i metody. W opracowaniu użyto metody prospektywnej dla oceny poziomu bólu - polskiej wersji skali Critical Care Pain Observation Tool. Grupa badana składała się z pacjentów dwóch oddziałów intensywnej terapii - ogólnego i neurochirurgicznego, którzy byli wentylowani mechanicznie, zaintubowani lub z tracheostomią.

Wyniki. Badaniem objęto 72 ciężko chorych, wentylowanych mechanicznie pacjentów. Ból był oceniany podczas procedur nocyceptywnych. Mediana poziomu bólu ocenianego zgodnie ze skalą CPOT wynosiła 1, z maksymalną wartością 8 punktów i minimalną 0 punktów. Wyniki wskazują na dobre zabezpieczenie przeciwbólowe pacjentów.

Wnioski. Poziom bólu w całej ocenianej grupie pacjentów był niski. W większości przypadków nie obserwowano behawioralnych zmian w odpowiedzi na ból. Istnieje korelacja pomiędzy fizjologicznymi i behawioralnymi wskaźnikami w odpowiedzi na ból.

SŁOWA KLUCZOWE: ból, intensywna terapia, skala CPOT.

\section{Wprowadzenie}

Ból definiowany jest jako subiektywne, negatywne odczucie mające podłoże tak zmysłowe, jak i emocjonalne, które powstaje pod wpływem czynników, które doprowadzają do uszkodzenia tkanek bądź zagrażają ich uszkodzeniem [1]. Zjawisko bólu u pacjenta towarzyszy wielu sytuacjom klinicznym i zważywszy na negatywne

\section{ABSTRACT}

Introduction. According to the definition, pain is a subjective phenomenon whose intensity can be subjectively described by the person feeling the pain. There are many groups of pa-tients who, for various reasons, are unable to verbalize the pain they feel. Assessing the pain felt by patients treated in intensive care units is a challenge due to sedation, verbal communication disorders or artificial respiration.

Aim. The aim of the study was assessing pain using behavioral pain indicators based on the Polish version of Critical Care Pain Observation Tool (CPOT).

Material and methods. The study used the prospective method, and for assessing the level of pain - Polish version of pain assessment scales Critical Care Pain Observation Tool (CPOT). The research group consisted of two intensive care units - general and neurosurgical one, who are mechanically ventilated, intubated or with tracheotomy.

Results. The study included 72 severely ill, mechanically ventilated patients; pain was as-sessed during nociceptive procedure. In the study group the median of pain level according to CPOT was 1 point, with the maximum value of 8 points and the minimum of 0 . The results indicate good analgesic protection of patients. Conclusions. The level of pain for the whole group of patients was low. In majority of obser-vation no behavioural response to pain was noted. There is a correlation between physiologi-cal and behavioural factors in response to pain.

KEYWORDS: pain, critical care, CPOT scale.

dobrze poznane skutki bólu, powinno ono być oceniane i niwelowane. Ból może powodować szereg zaburzeń na poziomie narządów i tkanek, przyczyniając się do zwiększenia poziomu endogennych katecholamin, co z kolei doprowadza do przyspieszenia czynności serca, liczby oddechów, wzrostu ciśnienia tętniczego, skutkując zwiększonym zapotrzebowaniem na tlen, zwięk- 
szonym jego zużyciem, a w konsekwencji pogorszeniem przepływu narządowego i tkankowego, z hipoksją i nasileniem reakcji katabolicznej włącznie [2-4]. Istnieją wyniki potwierdzające wpływ bólu na zwiększoną zachorowalność i śmiertelność [5].

Zgodnie z definicją ból jest zjawiskiem subiektywnym, czyli jego natężenie może określić subiektywnie osoba doznająca bólu, jednakże jest wiele grup pacjentów, którzy z różnych przyczyn nie są w stanie bólu werbalizować. Tą szczególną grupą pacjentów są chorzy leczeni na oddziale intensywnej terapii, często poddani sedacji, z zaburzeniami komunikacji werbalnej wynikającymi albo z ograniczeń świadomości i przytomności, albo z konieczności wytworzenia sztucznej drogi oddechowej. U pacjentów ciężko chorych powinno się oceniać ból na podstawie objawów podmiotowych, ale również na podstawie zachowania się chorego: wyrazu i ekspresji twarzy, grymasu twarzy, wokalizacji, napięcia mięśniowego [5]. Doznania bólowe związane z procedurami inwazyjnymi, jak również wynikające ze stanu klinicznego w świetle danych literatury przedmiotu dotykają ponad 50\% pacjentów ciężko chorych i są oceniane jako ból o natężeniu od średniego po ciężki [6]. Badania wskazują, że ci pacjenci najczęściej odczuwają ból związany z inwazyjnym monitorowaniem funkcji życiowych, inwazyjnymi procedurami diagnostycznymi, wentylacją mechaniczną, czynnościami pielęgnacyjnymi, takimi jak: zmiana ułożenia, oczyszczanie dróg oddechowych i bolesna zmiana opatrunków [6-8].

Celem badań była ocena bólu w oparciu o wskaźniki behawioralne bólu na podstawie polskiej wersji skali Critical Pain Observation Tool (CPOT).

Cele szczegółowe:

1. Ocena częstotliwości obserwowanych behawioralnych objawów bólu podczas wykonywania procedur nocyceptywnych.

2. Ocena zależności pomiędzy fizjologicznymi a behawioralnymi wskaźnikami bólu podczas wykonywania procedur nocyceptywnych.

\section{Materiał i metody}

$\mathrm{Na}$ przeprowadzenie badań uzyskano zgodę Komisji Bioetycznej przy Uniwersytecie Medycznym im. Karola Marcinkowskiego w Poznaniu. Autorzy zostali zwolnieni z obowiązku uzyskania pisemnej zgody osób badanych.

W badaniach zastosowano metodę prospektywną, z wykorzystaniem standaryzowanych narzędzi do oceny poziomu bólu, sedacji, stanu ciężkości i stanu świadomości. Technikami badań były obserwacja zachowania pacjentów w odpowiedzi na bodźce nocyceptywne związane z mechanicznym oczyszczanie dróg oddechowych i zmianą ułożenia chorego oraz analiza dokumentacji medycznej badanych.
W celu oceny poziomu bólu posłużono się polską wersją skali oceny bólu CPOT [9]. Skala CPOT została opracowana w Kanadzie, gdzie była poddana procesowi standaryzacji w grupie 105 pacjentów kardiochirurgicznych nieprzytomnych i zaintubowanych oraz przytomnych i zaintubowanych; uzyskano zadowalające parametry psychometryczne. Według skali CPOT oceniane są cztery behawioralne wskaźniki bólu: wyraz twarzy, ruchy ciała, dostosowanie się do respiratora oraz wokalizacja (w przypadku pacjentów oddychających samodzielnie), a także napięcie mięśniowe. Każdy z tych wskaźników jest punktowany od 0 do 2, gdzie 0 oznacza brak reakcji w odpowiedzi na bodziec bólowy, 1 oznacza umiarkowaną reakcję na bodziec i 2 oznacza silną odpowiedź pacjenta na ból.

Dodatkowo oceniano wartości parametrów życiowych, takich jak SBP, DBP i MAP, tętno, RR oraz $\mathrm{SpO}_{2}$. Do oceny stopnia sedacji wykorzystano skalę Ramsaya [10], stan ciężkości badanych oceniano na podstawie skali APACHE II [11].

Pacjenci byli obserwowani przez pielęgniarki anestezjologiczne, które wyraziły zgodę na udział w badaniu. Przed zbieraniem danych pielęgniarki otrzymały teoretyczny i praktyczny instruktaż oceny bólu i zastosowania skali CPOT.

Ocenę bólu prowadzono u 72 pacjentów podczas wykonywania czynności pielęgniarskich określanych jako nocyceptywne, takich jak: mechaniczne oczyszczanie drzewa oskrzelowego, zmiana pozycji i zmiana opatrunków. Łącznie przeprowadzono 72 obserwacje zachowania się pacjenta podczas ww. procedur. Każdego pacjenta obserwowano jeden raz.

Grupę badanych stanowili pacjenci leczeni na dwóch oddziałach intensywnej terapii ogólnym i neurochirurgicznym, wentylowani mechanicznie, zaintubowani lub z tracheostomią. Kryterium włączenia do badań stanowili pacjenci, którzy prezentowali problemy z werbalizacją bólu, bez ubytków neurologicznych w postaci porażeń lub niedowładów oraz pełnoletni, który nie byli pod wpływem alkoholu czy środków odurzających. W badanej grupie wyodrębniono cztery podgrupy pacjentów: otrzymujących leki przeciwbólowe, nieotrzymujących leków przeciwbólowych, otrzymujących leki sedatywne, nieotrzymujących leków sedatywnych.

W analizie statycznej wykorzystano statystyki opisowe adekwatne do uzyskanych danych. Dla zmiennych interwałowych wykorzystano średnią arytmetyczną oraz odchylenie standardowe, dla zmiennych porządkowych natomiast wykorzystano medianę, wartości minimalne i maksymalne oraz wartości kwartyli dolnego i górnego. Dla zmiennych nominalnych określono liczbę (n) oraz procentową wartość udziału danej zmiennej. W celu oceny korelacji pomiędzy zmiennymi obliczono współ- 
Czynnik korelacji rangowej $r_{s}$ Spearmana, natomiast różnice pomiędzy zmiennymi oszacowano za pomocą testu nieparametrycznego Manna-Withneya. Poziom istotności statystycznej przyjęto $p<\alpha$. Analizy statystycznej dokonano w programie Statistica 10,0.

\section{Wyniki}

W badaniu uczestniczyło 72 pacjentów: 33 kobiety (45,8\%) i 39 mężczyzn (54,1\%). Średnia wieku badanych wyniosła 58,1 roku ( $\pm 15,3$ roku). Wszyscy pacjenci byli poddani inwazyjnej wentylacji mechanicznej, zaintubowani lub z tracheostomią. Spośród badanych 37,5\% pacjentów otrzymywało leki przeciwbólowe, natomiast u 62,5\% pacjentów nie zastosowano osłony przeciwbólowej. Leki uspokajające otrzymywało 68\% pacjentów, natomiast $32 \%$ pacjentów nie podawano sedacji. Mediana punktacji stopnia sedacji dla całej grupy badanej według skali Ramseya wynosiła 4 punkty (minimum 1 i maksimum 6 punktów) przy wartościach kwartyli 2 i 6. Kliniczny stan ciężkości oceniany w skali APACHE ॥ wynosił dla ogółu badanych 24 punkty (minimum 9 i maksimum 87 punktów), wartości kwartyli dolnego i górnego odpowiednio 14 i 36. Stan świadomości według skali Glasgow w badanej grupie wynosił 7 punktów (3 i maks. 15 punktów) oraz kwartyli 3 i 11 (Tabela 1).

Tabela 1. Charakterystyka demograficzna badanych Table 1. Demographic characteristics of the study group

\begin{tabular}{cc}
\hline Zmienna/Variable & $\mathrm{n}(\%)$ \\
\hline $\begin{array}{c}\text { Płeć/Sex } \\
\text { mężczyźni/men }\end{array}$ & $33(45,8)$ \\
Pacjenci otrzymujący leki przeciwbólowe/ & $39(54,1)$ \\
Patients receiving painkillers & $27(37,5)$ \\
Pacjenci nieotrzymujący leków przeciwbólowych/ & $45(62,5)$ \\
Patients not receiving painkillers & \\
Pacjenci pod wpływem leków uspokajających/ & $49(68,5)$ \\
Patients receiving sedatives & \\
Pacjenci bez leków uspokajających/ & \\
Patients not receiving sedatives & $23(31,9)$ \\
APACHE II (mediana/min.-maks.)/ & \\
APACHE II (median/min.-max.) & \\
Skala Ramseya/Ramsey Scale & \\
Skala Glasgow/Glasgow Scale & \\
\hline
\end{tabular}

Źródło: opracowanie własne

Source: author's own analysis

Poziom bólu mierzony za pomocą skali oceny bólu CPOT dla ogółu badanych wynosił 1 punkt (0-8) przy wartościach kwartyli 0 i 3. Dla osób, które otrzymywały leki przeciwbólowe, poziom sedacji wyniósł 4 punkty (1-6), stan świadomości wyniósł 8 (3-15), zaś poziom bólu w skali CPOT równał się 2 punkty (0-8) przy wartościach kwartyli 0 i 3 . Dla badanych nieotrzymujących leku przeciwbólowego poziom bólu na podstawie skali CPOT wyniósł 0 punktów (0-8) przy wartościach kwartyli 0 i 2. Dla badanych, którzy byli pod wpływem leków uspokajających, poziom bólu wyniósł 0 punktów (0-8), a wartości kwartyli równały się odpowiednio 0 i 3, zaś dla pacjentów, którzy nie byli pod wpływem leków uspokajających, wynosił 2 punkty (0-4) przy wartościach kwartyli 0-3 (Tabela 2).

Mediana punktacji wskaźnika „wyraz twarzy” dla ogółu badanych wynosiła 0 (0-2), co oznacza, że pacjent był zrelaksowany i nie prezentował reakcji bólowej. Mediana punktacji wskaźnika „ruchy ciała” wynosiła 0 (0-2), wskaźnika „dostosowanie do respiratora” - 0 (0-2), wskaźnika „napięcie mięśniowe” - również 0 (0-2). W większości ocen zanotowano brak odpowiedzi podczas procedury nocyceptywnej. Zakres punktacji statystyk opisowych poszczególnych wskaźników zachowania w odpowiedzi na bodziec bólowy zaszeregowanych w skali CPOT w poszczególnych podgrupach badanych przedstawiono w tabeli 2.

Tabela 2. Statystyki opisowe dla wskaźników bólu skali CPOT Table 2. Descriptive statistics for CPOT Scale pain indicators

\begin{tabular}{|c|c|c|c|c|c|c|}
\hline $\begin{array}{c}\text { Grupy } \\
\text { pacjentów/ } \\
\text { Groups of } \\
\text { patients }\end{array}$ & $\begin{array}{l}\text { Wskaźniki bólu/ } \\
\text { Pain indicators }\end{array}$ & $\begin{array}{c}\text { Mediana/ } \\
\text { Median }\end{array}$ & $\begin{array}{l}\text { Wartości } \\
\text { / minimalne/ } \\
\text { Minimal } \\
\text { values }\end{array}$ & $\begin{array}{l}\text { Wartości } \\
\text { maksymalne/ } \\
\text { Maximal } \\
\text { values }\end{array}$ & $\begin{array}{c}\text { Dolny } \\
\text { / kwartyl/ } \\
\text { Lower } \\
\text { quartile }\end{array}$ & $\begin{array}{c}\text { Górny } \\
\text { kwartyl/ } \\
\text { Upper } \\
\text { quartile }\end{array}$ \\
\hline \multirow{4}{*}{$\begin{array}{c}\text { Pacjenci } \\
\text { z analgezją/ } \\
\text { Patients with } \\
\text { analgesia }\end{array}$} & $\begin{array}{c}\text { Wyraz twarzy/ } \\
\text { Facial expression }\end{array}$ & 1 & 0 & 2 & 0 & 1 \\
\hline & $\begin{array}{c}\text { Ruchy ciała/ } \\
\text { Body movements }\end{array}$ & 0 & 0 & 2 & 0 & 1 \\
\hline & $\begin{array}{l}\text { Dostosowanie do } \\
\text { respiratora/ } \\
\text { Compliance with } \\
\text { ventilator }\end{array}$ & 0 & 0 & 0 & 0 & 1 \\
\hline & $\begin{array}{l}\text { Napięcie mięśniowe/ } \\
\text { Muscular tension }\end{array}$ & 0 & 0 & 2 & 0 & 1 \\
\hline \multirow{4}{*}{$\begin{array}{l}\text { Pacjenci } \\
\text { bez leków } \\
\text { przeciwbólo- } \\
\text { wych/ } \\
\text { Patients not } \\
\text { receiving } \\
\text { painkillers }\end{array}$} & $\begin{array}{l}\text { Wyraz twarzy/ } \\
\text { Facial expression }\end{array}$ & 0 & 0 & 2 & 0 & 1 \\
\hline & $\begin{array}{c}\text { Ruchy ciała/ } \\
\text { Body movements }\end{array}$ & 0 & 0 & 2 & 0 & 0 \\
\hline & $\begin{array}{l}\text { Dostosowanie do } \\
\text { respiratora/ } \\
\text { Compliance with } \\
\text { ventilator }\end{array}$ & 0 & 0 & 2 & 0 & 0 \\
\hline & $\begin{array}{l}\text { Napięcie mięśniowe/ } \\
\text { Muscular tension }\end{array}$ & 0 & 0 & 1 & 0 & 0 \\
\hline \multirow{4}{*}{$\begin{array}{l}\text { Pacjenci } \\
\text { poddani } \\
\text { działaniu } \\
\text { leków uspo- } \\
\text { kajających/ } \\
\text { Patients } \\
\text { receiving } \\
\text { sedatives }\end{array}$} & $\begin{array}{l}\text { Wyraz twarzy/ } \\
\text { Facial expression }\end{array}$ & 0 & 0 & 2 & 0 & 1 \\
\hline & $\begin{array}{c}\text { Ruchy ciała/ } \\
\text { Body movements }\end{array}$ & 0 & 0 & 2 & 0 & 1 \\
\hline & $\begin{array}{l}\text { Dostosowanie do } \\
\text { respiratora/ } \\
\text { Compliance with } \\
\text { ventilator }\end{array}$ & 0 & 0 & 2 & 0 & 1 \\
\hline & $\begin{array}{l}\text { Napięcie mięśniowe/ } \\
\text { Muscular tension }\end{array}$ & 0 & 0 & 1 & 0 & 0 \\
\hline
\end{tabular}




\begin{tabular}{|c|c|c|c|c|c|c|}
\hline \multirow{4}{*}{$\begin{array}{l}\text { Pacjenci bez } \\
\text { sedacji// } \\
\text { Patients not } \\
\text { receiving } \\
\text { sedatives }\end{array}$} & $\begin{array}{c}\text { Wyraz twarzy/Facial } \\
\text { expression }\end{array}$ & 1 & 0 & 1 & 0 & 1 \\
\hline & $\begin{array}{l}\text { Ruchy ciała/Body } \\
\text { movements }\end{array}$ & 0 & 0 & 2 & 0 & 1 \\
\hline & $\begin{array}{l}\text { Dostosowanie do } \\
\text { respiratora/ } \\
\text { Compliance with } \\
\text { ventilator }\end{array}$ & 0 & 0 & 2 & 0 & 1 \\
\hline & $\begin{array}{l}\text { Napięcie mięśniowe/ } \\
\text { Muscular tension }\end{array}$ & 0 & 0 & 1 & 0 & 0 \\
\hline
\end{tabular}

Źródło: opracowanie własne

Source: author's own analysis

Podczas oceny bólu obserwowano z różną częstotliwością poszczególne zachowania pacjentów, które stanowią parametry skali oceny bólu CPOT. U większości badanych nie obserwowano oznak bólu w zakresie ocenianych zmiennych. Poziom wynosił 0 punktów, zdecydowanie rzadziej obserwowane były oznaki bólu oceniane na 1 punkt w zakresie ocenianych zmiennych, natomiast najrzadziej punktowano zmienne maksymalnie (Tabela 3).

Tabela 3. Częstotliwość występowania behawioralnych wskaźników bólu Table 3. Frequency of incidence of behavioral pain indicators

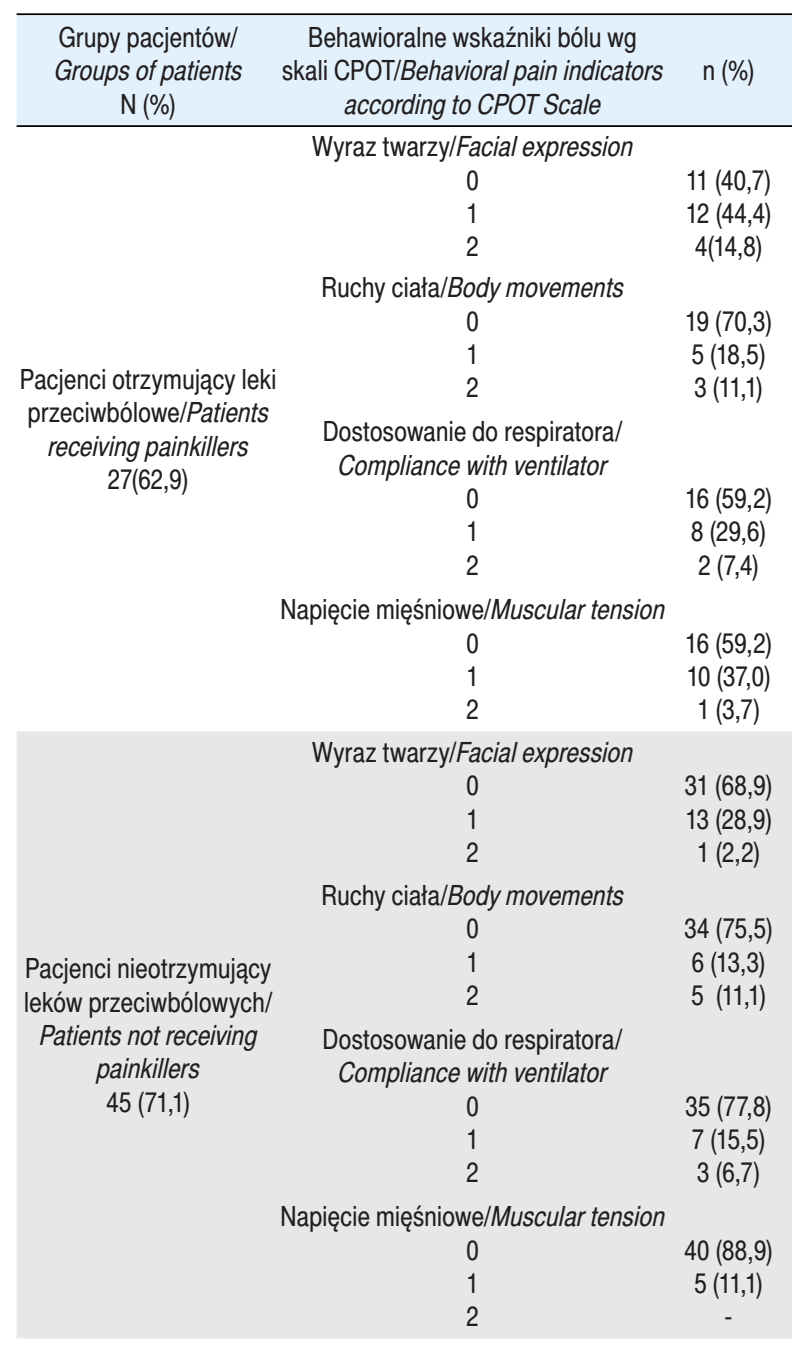

\begin{tabular}{|c|c|c|}
\hline & Wyraz twarzy/Facial expression & \\
\hline & 0 & $32(65,3)$ \\
\hline & 1 & $12(24,4)$ \\
\hline & 2 & $5(10,2)$ \\
\hline & Ruchy ciała/Body movements & \\
\hline & 0 & $32(65,3)$ \\
\hline & 1 & $12(24,9)$ \\
\hline & 2 & $5(10,2)$ \\
\hline $\begin{array}{l}\text { leki sedatywne/Patients } \\
\text { receiving sedatives }\end{array}$ & $\begin{array}{l}\text { Dostosowanie do respiratora/ } \\
\text { Compliance with ventilator }\end{array}$ & \\
\hline & 0 & $36(73,5)$ \\
\hline & 1 & $8(16,3)$ \\
\hline & 2 & $4(8,1)$ \\
\hline & Vapięcie mięśniowe/Muscular tension & \\
\hline & 0 & $39(79,6)$ \\
\hline & 1 & $8(16,3)$ \\
\hline & 2 & $2(4,08)$ \\
\hline & Wyraz twarzy/Facial expression & \\
\hline & 0 & $10(43,6)$ \\
\hline & 1 & $13(56,5)$ \\
\hline & 2 & - \\
\hline & Ruchy ciała/Body movements & \\
\hline & 0 & $16(69,6)$ \\
\hline Pacjenci nieotrzymujący & 1 & $4(17,3)$ \\
\hline leków sedatywnych/ & 2 & $3(13,04)$ \\
\hline $\begin{array}{l}\text { Patients not receiving } \\
\text { sedatives }\end{array}$ & $\begin{array}{l}\text { Dostosowanie do respiratora/ } \\
\text { Compliance with ventilator }\end{array}$ & \\
\hline $23(31,9)$ & 0 & $15(30,4)$ \\
\hline & 1 & $7(30,4)$ \\
\hline & 2 & $1(4,3)$ \\
\hline & Vapięcie mięśniowe/Muscular tension & \\
\hline & 0 & $18(78,2)$ \\
\hline & 1 & $5(21,7)$ \\
\hline & 2 & - \\
\hline
\end{tabular}

Źródło: opracowanie własne

Source: author's own analysis

Średnie wartości tętna podczas bodźcowania w całej grupie badanej wynosiły 82,6 /minutę ( $\pm 18,6)$, średnie wartości ciśnienia tętniczego (MAP) wynosiły dla ogółu badanych 71,3 $( \pm 30,7)$, średnia liczba oddechów (RR) wynosiła 19,9/minute $( \pm 3,6)$, natomiast średnie saturacji krwi tętniczej $\left(\mathrm{SpO}_{2}\right)$ równały się 97,4\% $( \pm 2,1)$. Nie wykazano różnic $w$ wartościach MAP u osób, które otrzymywały lek przeciwbólowy i nie otrzymywały analgezji $(p>0,05)$, natomiast zanotowano istotną różnicę statystyczną w RR $(p=0,01)$. W podgrupie pacjentów otrzymujących leki sedatywne różnice istotne statystycznie dotyczyły jedynie wartości MAP $(p=0,00)$. MAP było wyższe podczas wykonywania procedury bólowej w grupie pacjentów, którzy nie otrzymywali leków uspokajających. Mediana poziomu sedacji ocenianej wg skali Ramseya wynosiła 4 (1-6).

W celu oceny zależności pomiędzy klinicznym stanem ciężkości wyrażonym punktacją w skali APACHE II a poziomem bólu wyrażonym punktacją w skali CPOT wykorzystano test korelacji rang Spearmana. Analiza nie wykazała zależności tak w całej grupie badanych, jak i w grupie badanych kobiet i mężczyzn. Natomiast wykazano istotnie statystyczną zależność 
pomiędzy stanem klinicznym a poziomem bólu w grupie pacjentów, którzy otrzymywali leki przeciwbólowe $\left(r_{s}=0,3, p=0,04\right)$. Wykazano także istotną statystycznie zależność pomiędzy stanem ciężkości a poziomem bólu u pacjentów, którzy nie otrzymywali terapii przeciwbólowej $\left(r_{s}=-0,3, p=0,02\right)$. Nie wykazano natomiast zależności pomiędzy poziomem bólu a poziomem sedacji wyrażonej punktacją w skali Ramsaya. W celu oceny zależności pomiędzy wskaźnikami fizjologicznymi i poziomem bólu wykorzystano test korelacji rang Spearmana. Wykazano silną zależność istotą statystycznie pomiędzy badanymi zmiennymi $\left(r_{s}=, 8\right.$, $p=0,00$ ) zarówno w całej grupie badanej, jak i w podgrupach mężczyzn i kobiet oraz w podgrupach pacjentów otrzymujących leki przeciwbólowe i nieotrzymujących leków przeciwbólowych, poddanych sedacji i nieotrzymujących sedacji.

Ocenie statystycznej poddano również zależność pomiędzy stopniem sedacji a poziomem odczuwanego bólu. Wykazano w całej grupie oraz wśród kobiet i mężczyzn istotną statystycznie zależność, gdzie $r_{s}>0$ i $p=0,05$, a także w podgrupie pacjentów, którzy nie otrzymywali leku przeciwbólowego, a byli sedowani $\left(r_{s}=-0,5, p=0,00\right)$.

\section{Dyskusja}

Ból, będąc zjawiskiem subiektywnym, zawsze stanowił element trudny do oceny. Tym większej trudności dostarcza jego rozpoznanie u pacjentów ciężko i krytycznie chorych. Niemożność werbalizacji u większości tych pacjentów skłania do poszukiwania i oceny pozawerbalnych wskaźników dostarczających informacji o poziomie bólu w tej grupie chorych w celu lepszej jego oceny i lepszego monitorowania leczenia. Dlatego też w opracowaniach Polskiego Towarzystwa Badania Bólu znalazły się rekomendacje dotyczące także oceny behawioralnej bólu w różnych grupach chorych, którzy mają problemy, na różnym poziomie, z komunikacją i wyrażaniem tym samym swoich odczuć dotyczących dolegliwości bólowych [12].

Celem badań własnych była ocena behawioralna bólu w oparciu o formularz skali CPOT. Badania prowadzono w grupie 72 ciężko chorych, wentylowanych mechanicznie pacjentów, a ból oceniano w trakcie procedury nocyceptywnej. W badanej grupie mediana poziomu bólu wg CPOT wynosiła 1 punkt, przy wartości maksymalnej 8 punktów, a minimalnej 0 . Wynik wskazuje na dobre zabezpieczenie przeciwbólowe pacjentów. Są to wartości porównywalne z innymi badaniami prowadzonymi w oparciu o wskaźniki behawioralne skali CPOT [13]. Nieco różniły się wyniki otrzymane przez badaczy z Korei. Badali oni poziom bólu związany z procedurą oczyszczania dróg oddechowych u pacjentów po uszkodzeniu mózgu ( $n=31)$. Obserwowano ból w większości na poziomie 1, jeszcze przed zadziałaniem bodźca, zaś podczas bodźcowania poziom bólu wynosił średnio 2,58-3,26 i był istotnie statystycznie większy od poziomu przed odsysaniem drzewa oskrzelowego [14]. Tendencje wzrostu poziomu bólu, medianę 2 pkt wartości skali CPOT zanotowali także Echegaray-Benites i wsp., którzy oceniali w grupie pacjentów neurochirurgicznych zachowanie w odpowiedzi na bodziec bólowy związany ze zmianą ułożenia chorego [15]. Bardzo zbliżona odpowiedź bólowa była zanotowana podczas badań prowadzonych przez Rijkenberg i wsp., którzy uzyskali medianę równą 0 wartości skali CPOT w czasie spoczynku i wzrost do 2 w czasie wykonywania procedury nocyceptywnej [16]. Takie wyniki wskazują na dość dobre zabezpieczenie przeciwbólowe pacjentów.

Głównym punktem analizy w prezentowanych badaniach własnych było oszacowanie częstości zachowań pacjenta podczas bólu. Pacjenci otrzymujący leki przeciwbólowe nie prezentowali w większości żadnej odpowiedzi na ból. Osiągane wyniki można tłumaczyć zabezpieczeniem przeciwbólowym za pomocą środków opioidowych, podawanych w ciągłych infuzjach. Bardzo podobne wyniki otrzymali Echegaray-Benites i wsp. - w większości nie było odpowiedzi widocznej w zachowaniu poszczególnych wskaźników bólu zaszeregowanych w skali CPOT [15]. Żaden wskaźnik bólu wchodzący w skład skali CPOT w badaniach własnych nie osiągnął maksymalnych wartości mediany, w przeciwieństwie do przywołanych wyżej badań, w których zanotowano wartość najwyższą mediany poziomu bólu, świadczącą o silnie odczuwanym bólu podczas zmiany pozycji pacjentów [15].

W przeprowadzonych badaniach własnych zanotowano również typowe zachowanie się parametrów życiowych pacjentów, które w czasie bodźcowania wykazywały tendencje wzrostowe, sugerujące nieadekwatne uspokojenie pacjenta. Jednakże wiele badań wskazuje, że wskaźniki fizjologiczne nie zawsze są oznaką bólu towarzyszącego pewnym procedurom, również prezentują tendencje wzrostowe przy procedurach niegenerujących doznań bólowych $[17,18]$.

Ograniczenia przytaczanych badań własnych wynikają przede wszystkim z homogenicznej i zbyt małej grupy pacjentów oraz z braku oceny bólu w spoczynku, po bodźcowaniu i 20 minut po procedurze. Skala CPOT wymaga zastosowania w dalszych badaniach pacjentów ciężko chorych, niezdolnych do werbalizowania bólu, przebywających na oddziałach anestezjologii i intensywnej terapii i określenia trafności i rzetelności jej polskiej wersji. 


\section{Wnioski}

1. Poziom bólu dla ogółu badanych w ocenie behawioralnej był niski.

2. W większości obserwacji nie notowano żadnej odpowiedzi behawioralnej na ból.

3. Istnieje zależność pomiędzy wskaźnikami fizjologicznymi i behawioralnymi w odpowiedzi na ból.

\section{Piśmiennictwo}

1. Marskey H, Bogduk $\mathrm{N}$ (red.). International Association for the Study of Pain IASP Task Force on Taxonomy. Part III: Pain terms, a current list with definitions and notes on Osage. Classification of chronic Pain. Seattle: IASP Press; 1994.

2. Puntillo K, Morris A, Thomson C, Stanik-Hutt J, White C, Wilg L. Pain behaviours observed during six common procedures: results from the Tunder Project II. Crit Care Med. 2004; 32: 421-427.

3. de Jong A, Molinari N, de Lattre S et al. Decreasing severe pain and serious adverse events while moving intensive care unit patients: a prospective interventional study (the NURSE - DO project). Crit Care. 2013; 17: 74.

4. Page D, Blakley W, Ben-Eliyahu S. Evidence that postoperative pain is a mediator of the tumor promoting effects of surgery in rats. Pain. 2001; 90: 191-199.

5. Shannon K, Bucknall T. Pain assessement in critical care: what we have Lenart from research. Intensive Crit Care Nurs. 2003; 19: 154-162.

6. Chanques G, Sebbane M, Barbotte E et al. A prospective study of pain at rest: incidence and characteristics of an unrecognised symptom in surgical and trauma versus medical intensive care unit patients. Anesthesiology. 2007; 107: 858-860.

7. Marmo L, Fowler S. Pain Assesment tool in the Criticaly ill post open heart surgery patient population. Pain Manage Nurs. 2010; 11: 134-140.

8. Puntillo KA, Max A, Timsit JF et al. Determinants of procedural pain intensity in the intensive care unit. The Europain (R) study. Am J Respir Crit Care Med. 2014; 189: 39-47.

9. Gelinas C, Fillion L, Puntillo KA et al. Validation of the Critical Care Pain Observation Tool in adult patients. Am J Crit Care. 2006; 15: 420-427.

10. Ramsay MAE, Savege TM, Simpson BRJ \& Goodwin R. Controlled sedation with alpaxalone-alphadolone. Brit Med J. 1974; 2: 656-659.
11. Knaus WA, Dreper E, Wagner DP. APACHE II: a severity of disease classification system. Crit Care Med. 1985.13; 818-829.

12. Misiołek H, Cettler M, Woroń J et al. Zalecenia postępowania w bólu pooperacyjnym Ad 2014. Ból. 2014; 14: 19-47.

13. Linde S, Badger J, Machan JT. Reevaluation of the critical-care pain observation tool in intubated adults after cardiac surgery. Am J Crit Care. 2013; 6: 491-497.

14. Lee K, Ob H, Sub Y, Seo W. Patterns and clinical correlates of pain among brain injury patients in critical care assessed with Critical Care Pain Observation Tool. Pain Manag Nurs. 2013; 14: 259-267.

15. Echegaray-Benites Ch, Kapoustina O, Gelinas C. Validation of the use of the Critical Care Observation Tool (CPOT) with brain surgery patients in the neurosurgical intensive care unit. Intensive Crit Care Nurs. 2014; 30: 257-265.

16. Rijkenberg S, Stilma W, Endeman $\mathrm{H}$ et al. Pain measurment in mechanically ventilated critically ill patients: Behavioral Pain Scale versus Critical Care Pain Observation Tool. J Crit Care. 2015; 30: 167-172.

17. Marmo L, Fowler S. Pain assessment tool in the critically ill post open hearth surgery patient population. Pain Manag Nurs. 2010; 11(3): 134-140.

18. Young J, Siffleet Jo, Nikoletti S et al. Use of Behavioural Pain Scale to assess pain in ventilated, unconcious and/or sedated patients. Intensive Crit Care Nurs. 2006; 22(1): 32-39.

Artykuł przyjęty do redakcji: 17.09.2017

Artykuł przyjęty do publikacji: 24.01.2018

Źródło finansowania: Praca nie jest finansowana z żadnego źródła. Konflikt interesów: Autorzy deklarują brak konfliktu interesów.

\author{
Adres do korespondencji: \\ Edyta Cudak \\ ul. Mariana Smoluchowskiego 11 \\ 60-179 Poznań \\ tel.: 618612239 \\ fax: 618612266 \\ e-mail: edytacud@ump.edu.pl \\ Zakład Pielęgniarstwa Anestezjologicznego i Intensywnej Opieki \\ Wydział Nauk o Zdrowiu \\ Uniwersytet Medyczny im. Karola Marcinkowskiego w Poznaniu
}

